\title{
Article \\ Molecular and Physiological Effects of Magnesium-Polyphenolic Compound as Biostimulant in Drought Stress Mitigation in Tomato
}

\author{
Haytham Hamedeh, Shaula Antoni, Lorenzo Cocciaglia and Valentina Ciccolini *
}

check for

updates

Citation: Hamedeh, H.; Antoni, S.;

Cocciaglia, L.; Ciccolini, V. Molecular and Physiological Effects of

Magnesium-Polyphenolic

Compound as Biostimulant in

Drought Stress Mitigation in Tomato.

Plants 2022, 11, 586. https://doi.org/

10.3390/plants11050586

Academic Editors: Ildikó Jócsák,

Ferenc Pál-Fám and

Sándor Keszthelyi

Received: 3 February 2022

Accepted: 21 February 2022

Published: 22 February 2022

Publisher's Note: MDPI stays neutral with regard to jurisdictional claims in published maps and institutional affiliations.

Copyright: (C) 2022 by the authors. Licensee MDPI, Basel, Switzerland. This article is an open access article distributed under the terms and conditions of the Creative Commons Attribution (CC BY) license (https:// creativecommons.org/licenses/by/ $4.0 /)$.
Department of Research and Development, FertiGlobal Division, SCL Italia S.p.A, Via Fabio Filzi, 25/A, 20124 Milan, Italy; hamedeh@fertiglobal.com (H.H.); antoni@fertiglobal.com (S.A.); cocciaglia@fertiglobal.com (L.C.)

* Correspondence: ciccolini@fertiglobal.com; Tel.: +39-0588-68877

\begin{abstract}
Plant biostimulants are being recognized as innovative tools to improve sustainable agricultural practices to mitigate the drastic effects of climate change, which is leading to a severe reduction in agricultural yields. In this work, a new biostimulant $\left(\mathrm{EnNuVi}{ }^{\circledR} \mathrm{ALPAN}^{\circledR}\right)$ was evaluated for its effectiveness on tomato (Solanum lycopersicum Mill. cv. Rio Grande) plants subjected to water deficit conditions. The molecular effects were elucidated through transcriptomic RNA-seq and gene expression $\mathrm{qPCR}$ analysis and the physiological responses were evaluated through qualitative analysis of pigments and proline content, membrane stability, and lipid peroxidation. ALPAN ${ }^{\circledR}$ was shown to adjust the transcriptional response by upregulating genes involved in source to sink carbohydrate metabolism and translocation, stomatal closure, and cell homeostasis. ALPAN ${ }^{\circledR}$ was shown to mitigate the deteriorating effects of water deficit on the physiological status of the plants by stabilizing the levels of the photosynthetic pigments, regulating the accumulation of osmo-protectants, and preserving the cell wall lipid bilayer from oxidation. In conclusion, transcriptomic and physiological analysis provided insightful information on the biostimulant effects, indicating a positive role of ALPAN $^{\circledR}$ foliar application in alleviating the negative costs of water deficit.
\end{abstract}

Keywords: $\mathrm{ALPAN}^{\circledR} ; \mathrm{EnNuVi}^{\circledR}$; polyphenols; water deficit; abiotic stress alleviation

\section{Introduction}

With the global population on the rise, it is expected to reach almost 10 billion by 2050 according to the United Nations [1], agricultural production is challenged to produce more while simultaneously facing a climate change disaster that is leading to the increase in extreme climatic events (drought, flooding, heat, salinity, etc.) either in frequency or intensity [2].

Drought, among these climatic events, is considered a major problem in crop production, and according to FAO (Food and Agriculture Organization), drought is responsible for almost $34 \%$ of total yield losses [3]. In addition to its effect on plant's productivity, the decrease in water availability triggers a wide array of responses that range from molecular, physiological, and biochemical to ecological events $[4,5]$. Upon exposure to drought, plants become more vulnerable to cell injury due to the increase in cellular production of reactive oxygen species (ROS) that takes place in the mitochondria and chloroplast [6]. This spike in ROS functions as an alarming signal to trigger acclimation to the uprising stress $[7,8]$. Moreover, drought can damage various biochemical and physiological processes such as photosynthesis, respiration, ion uptake [9], carbohydrate metabolism [10,11], and protein post translation modifications [12]. In severe drought conditions, those damages become irreversible because of the disturbed metabolism and impaired photosynthetic apparatus and, hence, the eventual death of the plant occurs. 
Due to their sessile nature, plants have evolved a wide range of mechanisms to respond to changes in their surrounding environment. Among such responses is the accumulation of plant's secondary metabolites [13]. Polyphenols, which are the largest group of plantspecialized metabolites, are recognized as compounds involved in stress protection in plants [14]. Phenolic compounds, being a part of the phenylpropanoid pathway, are known to be produced in higher amounts under stress conditions as they play a significant role in controlling plant's growth and development [15]. Additionally, nutrients fertilization has been proven to support plant growth and development under abiotic stress conditions by their direct role in the growth, metabolism, and biosynthesis of molecules in the plant cells that have a positive impact on a plant's growth and development $[16,17]$.

Among the available tools for farmers, plant-based biostimulants have gained more attention recently as low input crop management tools for sustainable agriculture. This type of biostimulants is being used to mitigate the negative and deleterious effects of water deficit under field/greenhouse conditions [18-20]. EnNuVi ${ }^{\circledR}$ (acronym: Enhance, Nurture and Vitalize) is a recently patented plant-derived biostimulants technology based on the complexation of the plant-derived pool of polyphenols with essential nutritive element(s) (e.g., $\mathrm{Cu}, \mathrm{Mg}, \mathrm{Mn}, \mathrm{Zn}$ ).

The aim of this work was to characterize the response of tomato seedlings sprayed with $A L P A N{ }^{\circledR}$, a magnesium-based $\mathrm{EnNuVi}^{\circledR}$ product, by investigating the physiological and molecular changes induced by water deficit and the potential positive effects of the foliar spraying in the mitigation of the harmful consequences of water deficit conditions. The molecular mechanism was revealed through transcriptomic (RNA-seq) and gene expression analysis (qPCR), while the physiological response was evaluated through the quantification of proteins and metabolites related to photosynthetic activity, osmoregulation, and cell integrity.

\section{Results}

\subsection{ALPAN ${ }^{\circledR}$ Treatment Preserved Photosynthesis in Tomato Seedlings under Water Deficit Condition}

The quantification of photosynthetic pigments involved in light absorption is a clue to the actual functional capacity of photosystems and, therefore, of the photosynthetic apparatus in general. Chlorophyll $a(\mathrm{chl} a)$ and chlorophyll $b(\mathrm{chl} b)$ can both bind to the light harvesting complex in the chloroplast to absorb blue and red light used for photosynthesis. Carotenoids, in turn, absorb blue light and are additionally involved in energy dissipation by heat through the xanthophyll cycle, quenching of ${ }^{1} \mathrm{O}_{2}$ formed during photo-oxidation, and regulation of thylakoid membrane fluidity [21]. Chloroplast pigment content is one of the most frequently used indicators of the plant tolerance status when exposed to several abiotic conditions including drought [22].

The mock water deficit (Mock + WD) plants showed a decrease in the level of chl $a$ one day after the start of the water deficit, and this decrease was sharper when the water deficit duration was extended to seven days (Figure 1a). Nonetheless, one day after the start of recovery (day 8), the concentration of $\mathrm{chl} a$ returned to a level comparable to that of the no stressed plants (Figure 1a), while chl $b$ showed a sharp accumulation in the Mock + WD plants (Figure 1b) as an attempt to compensate for the loss of chl $a$ to maintain the minimal electron flow into the electron transfer chain. The reduction in chl $a$ and the accumulation of $\operatorname{chl} b$ after seven days of stress, resulted in a very low chl $a / b$ (Figure 1c).

Moreover, the decrease in chl $a$ was accompanied by a gradual and significant decrease in carotenoids (Figure 1d), thus indicating a dysfunctional photosystem under water deficit conditions, which was restored to normality only when water was available again (day 8) (Figure 1d).

On the other hand, when ALPAN ${ }^{\circledR}$ was applied, the plants showed greater ability to alleviate the negative effects of water deficit compared to those observed in the Mock-WD plants (Figure 1). ALPAN ${ }^{\circledR}$-treated plants showed a better efficiency in the stabilization of the photosynthetic pigments (chlorophyll $a$, chlorophyll $b$ and carotenoids) at all the 
timepoints (Figure 1). The results observed confirm that the application of ALPAN ${ }^{\circledR}$ can contribute to improving the efficiency of photosynthesis by increasing or stabilizing the content of chloroplast pigments such as $\operatorname{chl} a, \operatorname{chl} b$, and carotenoids.

a

b
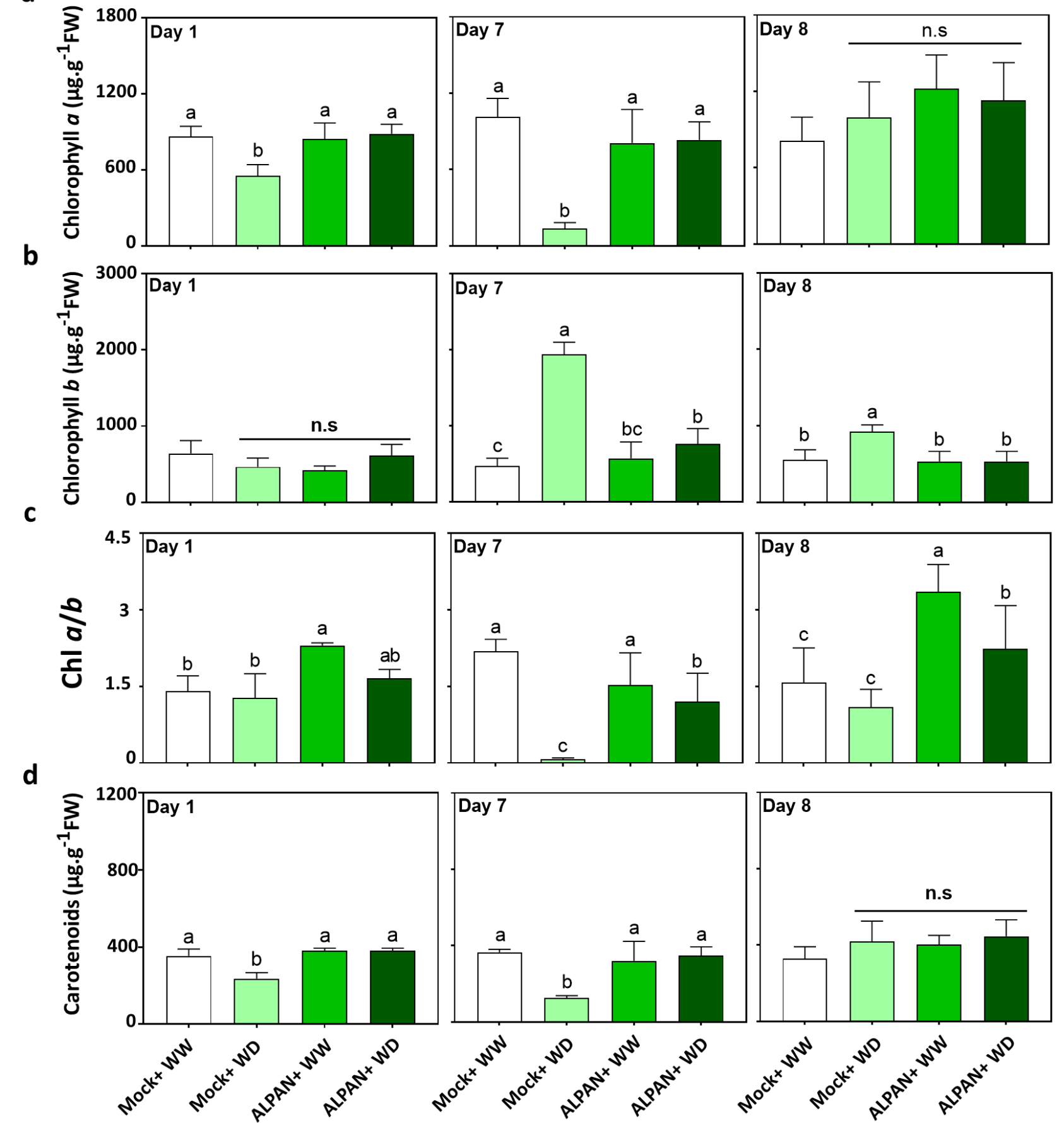

Figure 1. Concentrations of (a) Chlorophyll a, (b) Chlorophyll b, (c) chl $a / b$ ratio and (d) carotenoids after 1,7 , and 8 days of the initiation of the water deficit stress. WW = well watered; WD = water deficit; FW = fresh weight; n.s = not significant. Error bars above histogram columns represent the standard deviation of four independent biological replicates in each experimental group at each sampling timepoint. The statistical data were analyzed with the use of the one-way ANOVA and Tukey's post hoc tests, and a statistically significant difference $(p$-value $<0.05)$ is denoted by a different letter above a histogram column. 


\subsection{ALPAN ${ }^{\circledR}$ Treatment Alleviated Cell Damage and Protected Cellular Membranes in Tomato Seedlings under Water Deficit Condition}

The electrolyte leakage (EL) from plant tissues is often used as a parameter to assess cell integrity and for the initial detection of plant stress. Since membrane damage always results in an increased leakage of cytosolic constituents to the apoplastic space, higher values of EL implies lower membrane stability.

As noticed in Figure 2, Mock-WD plants showed a slight increase in the percentage of EL after one day of water deficit, whereas this increase was significantly higher after seven days of water deficit, and it remained high when regular watering was restored (day 8).

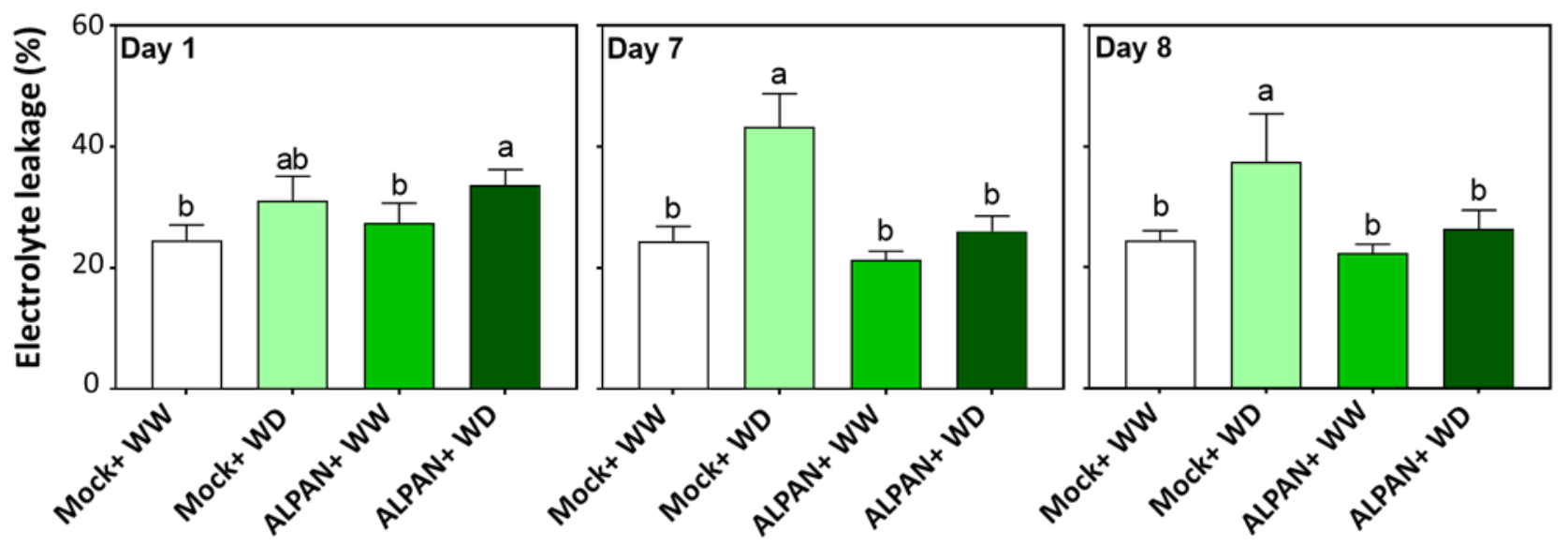

Figure 2. Electrolyte leakage determined after 1, 7, and 8 days of the initiation of the water deficit stress. WW = well watered, $\mathrm{WD}=$ water deficit. Error bars above histogram columns represent the standard deviation of four independent biological replicates in each experimental group at each sampling timepoint. The statistical data were analyzed with the use of the one-way ANOVA and Tukey's post hoc tests, and a statistically significant difference $(p$-value $<0.05)$ is denoted by a different letter above a histogram column.

Plants exposed to water deficit and treated with ALPAN $^{\circledR}$ showed a significant increase in EL during the early periods of water deficit (Figure 2, day 1, dark green bars), whereas at days seven and eight, ALPAN ${ }^{\circledR}$-treated plants showed a more significant reduction in $\mathrm{EL}$, hence maintaining more stable cellular membrane.

To evaluate more directly the extent of cellular damage experienced by tomato plants under water deficit, the level of lipid peroxidation was estimated through the accumulation of malondialdehyde (MDA) as an end product generated by oxidation of polyunsaturated fatty acids. The oxidative degradation or lipid peroxidation is a chain reaction created by reactive oxygen species that influence lipids containing a carbon-carbon double bond resulting in cellular damage.

MDA concentrations were similar after one day of water deficit in all the experimental groups (Figure 3), whereas on day seven of water deficit, the Mock + WD plants showed an increase in MDA levels, similar to ALPAN + WD plants. This increase might indicate the occurrence of lipid peroxidation and membrane damage once the plant is exposed to a prolonged duration of water deficit. While the Mock+ WD plants could not revert this process when the regular watering was restored (day 8), ALPAN ${ }^{\circledR}$-treated plants showed a significant reduction in MDA values. These results indicated that ALPAN $^{\circledR}$ application was efficient in avoiding irreversible damages in the cellular membrane. 

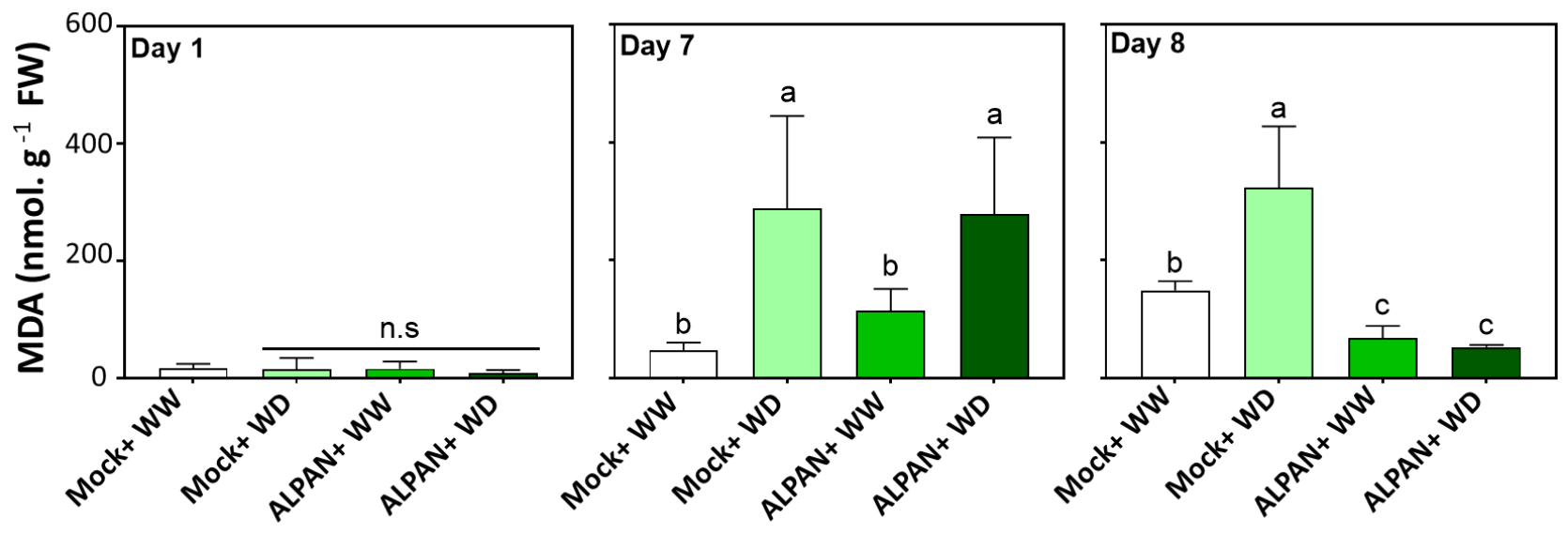

Figure 3. Malondialdehyde (MDA) concentration after 1, 7, and 8 days of the initiation of the water deficit stress. $\mathrm{WW}=$ well watered, $\mathrm{WD}=$ water deficit; $\mathrm{FW}=$ fresh weight; $\mathrm{n} . \mathrm{s}=$ not significant. Error bars above histogram columns represent the standard deviation of four independent biological replicates in each experimental group at each sampling timepoint. The statistical data were analyzed with the use of the one-way ANOVA and Tukey's post hoc tests, and a statistically significant difference $(p$-value $<0.05)$ is denoted by a different letter above a histogram column.

\subsection{ALPAN ${ }^{\circledR}$ Treatment Modulated Proline Levels in Tomato Seedlings under Water Deficit Condition}

Proline accumulation is one of the most important adaptative mechanisms for plants to cope with drought stresses, whereas higher levels can lead to adverse effects in maintaining the long-term tolerance mechanism.

The Mock-WD plants accumulated higher proline levels after 1 day of stress, and this accumulation continued to increase to reach triple the levels on day seven; the proline level did not further increase after rewatering (day 8) of plants but remained high (Figure 4, light green bars).
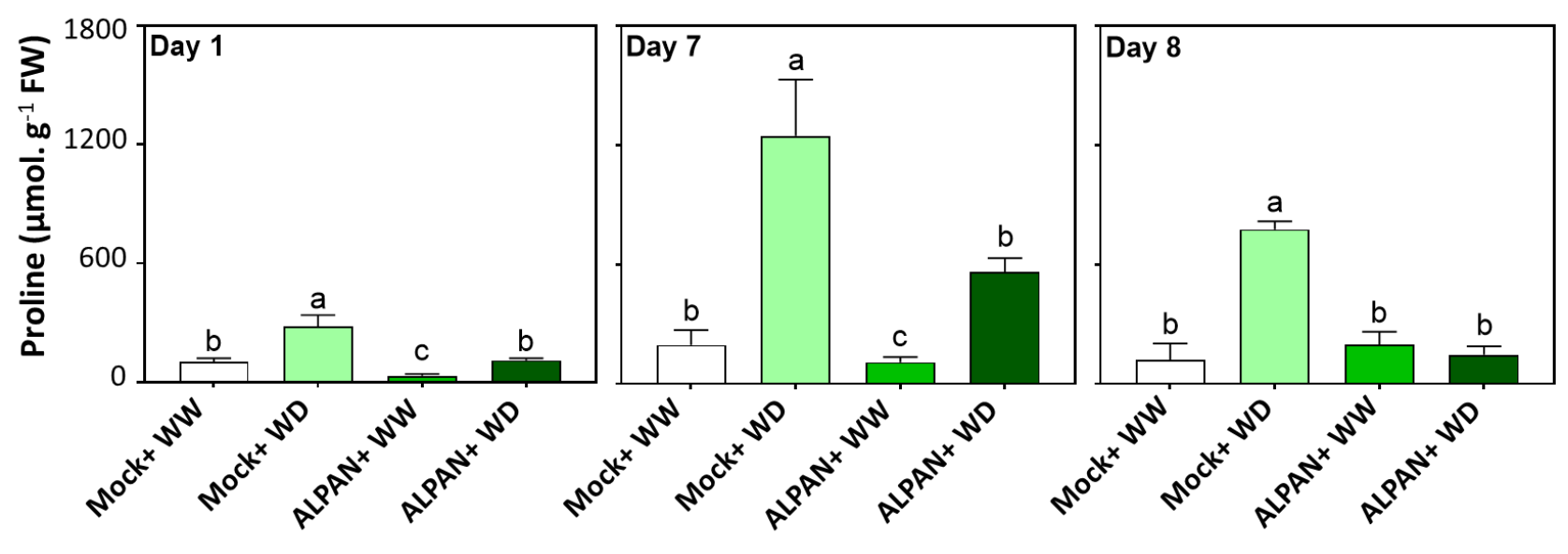

Figure 4. Proline concentration after 1, 7, and 8 days of the initiation of the water deficit stress. $\mathrm{WW}=$ well watered, $\mathrm{WD}=$ water deficit; FW = fresh weight. Error bars above histogram columns represent the standard deviation of four independent biological replicates in each experimental group at each sampling timepoint. The statistical data were analyzed with the use of the one-way ANOVA and Tukey's post hoc tests, and a statistically significant difference $(p$-value $<0.05)$ is denoted by a different letter above a histogram column.

By applying ALPAN $^{\circledR}$, proline accumulated less in the stressed plants at all experimental timepoints, and the restoration of the normal watering regime allowed the restoration 
of normal proline levels (Figure 4, dark green bars). Conversely, the Mock-WD plants continued to accumulate higher levels of proline even after $24 \mathrm{~h}$ of rewatering.

\subsection{ALPAN ${ }^{\circledR}$ Treatment Altered the Transcriptome in Tomato Seedlings under Water Deficit Condition}

RNA-seq data analysis revealed the molecular mechanism and the positive role of ALPAN $^{\circledR}$ in mitigating the adverse effects of drought stress. As indicated in Figure 5, plants treated with ALPAN ${ }^{\circledR}$ were shown to orchestrate various biological processes and molecular functions involved in post translation modifications of proteins by modifying proteolysis and protein dephosphorylation. Serine/threonine phosphatase was upregulated during the stress period, in addition to modifications inflicted on the structure of cellular organelles to improve the apoplastic movement of water and carbohydrates.

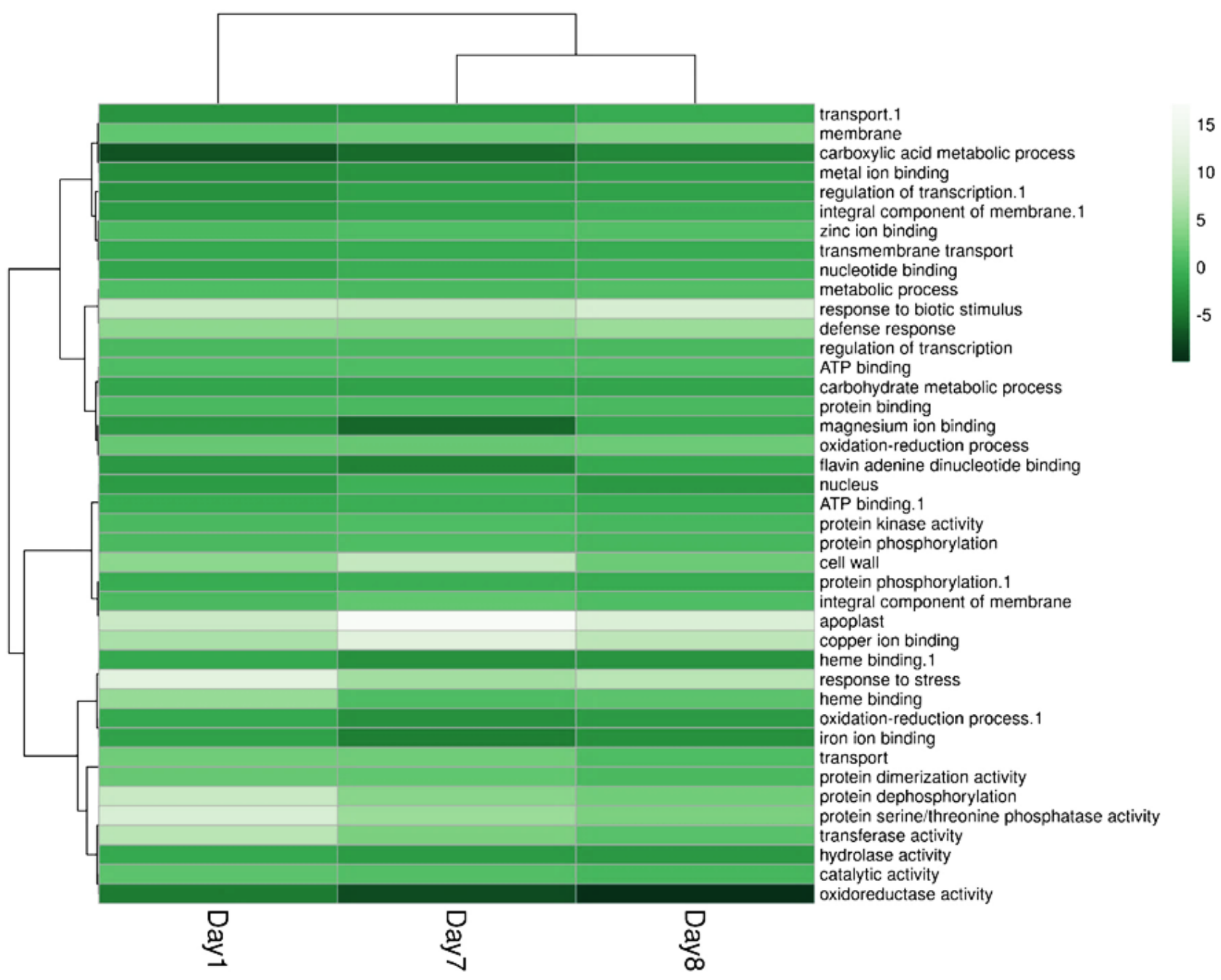

Figure 5. Hierarchical clustering of the main biological and molecular processes affected by ALPAN ${ }^{\circledR}$ treatment under water deficit conditions (ALPAN + WD) in comparison to Mock + WD at day 1, 7, and 8. Heatmap was generated using Clustvis online tool.

To confirm the results obtained from the RNA-seq analysis concerning the differentially expressed genes, we performed a gene expression analysis (qPCR) on specific genes involved in different functions under drought stress conditions. We quantified the expression of SITAS14, a drought responsive marker gene [23,24] that encodes for late embryogenesis abundance (LEA) protein involved in responses to abscisic acid and water deprivation. ALPAN ${ }^{\circledR}$-treated plants (ALPAN + WD) showed an upregulation in the ex- 
pression of SITAS14 during short and long water deficit periods (Figure 6). On the other hand, Mock + WD plants showed a slight increase in expression only one day after the initiation of water deficit stress. Nonetheless, this expression disappeared after seven days of stress.

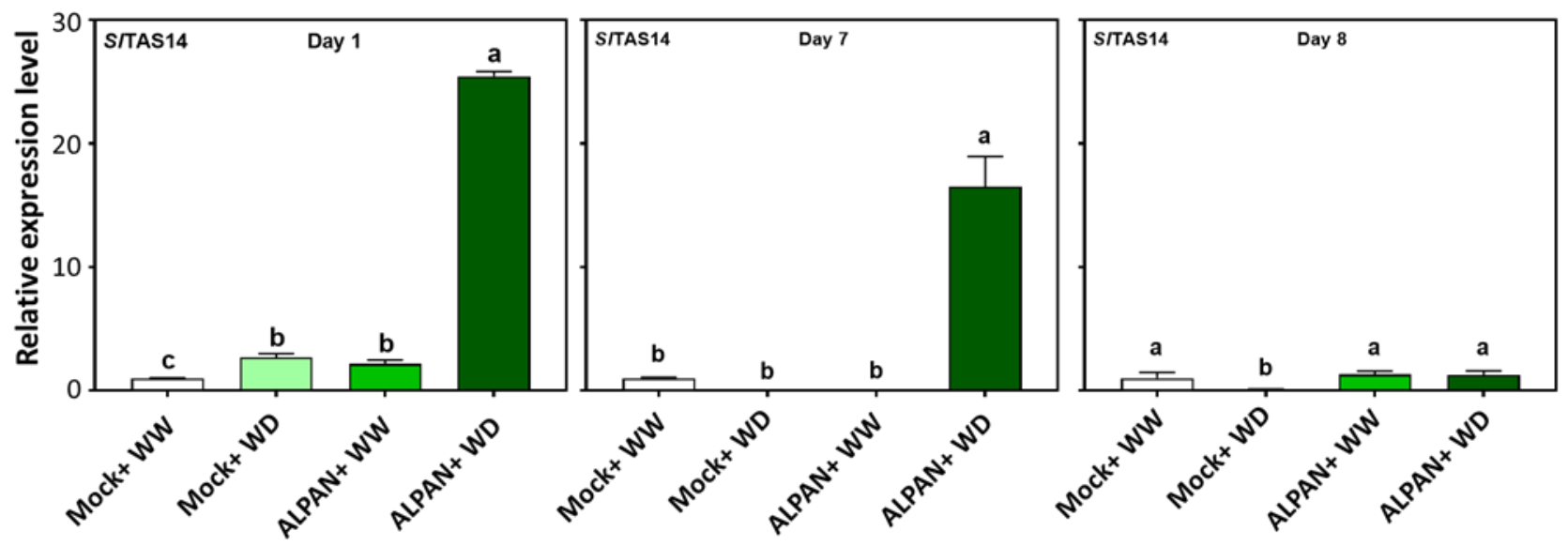

Figure 6. Expression levels of SITAS14 after 1, 7, and 8 of the initiation of the water deficit stress. $\mathrm{WW}=$ well watered, $\mathrm{WD}=$ water deficit. Error bars above histogram columns represent the standard deviation of four independent biological replicates in each experimental group at each sampling timepoint. The statistical data were analyzed with the use of the one-way ANOVA and Tukey's post hoc tests, and a statistically significant difference $(p$-value $<0.05)$ is denoted by a different letter above a histogram column.

Additionally, RNA-seq results were shown to modulate the expression of diverse metabolic processes involved in plant responses to water deficit. Among such processes is the tricarboxylic acid metabolism process (Krebs cycle) where the mitochondrial pyruvate dehydrogenase $(P D H)$ complex is the convergence point that regulates the flux of pyruvate derived from glycolysis into the tricarboxylic acid [25]. Our results indicated that ALPAN ${ }^{\circledR}$ was able to enhance the expression of the first subunit of the SIPDH complex during the later stages (day 7) of water stress (Figure 7).
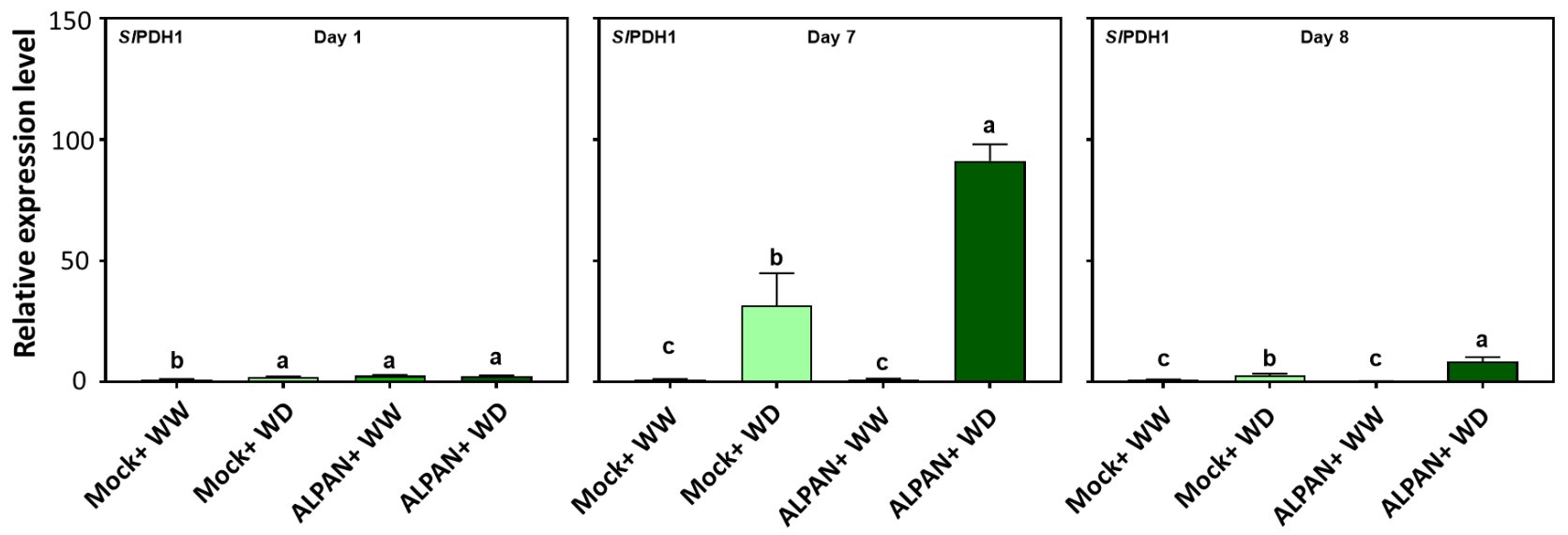

Figure 7. Expression levels of SLPDH1 after 1, 7, and 8 days of the initiation of the water deficit stress. $\mathrm{WW}=$ well watered, $\mathrm{WD}=$ water deficit. Error bars represent the standard deviation of four independent biological replicates in each experimental group at each sampling timepoint. The statistical data were analyzed with the use of the one-way ANOVA and Tukey's post hoc tests, and a statistically significant difference $(p$-value $<0.05)$ is denoted by a different letter above a histogram column. 
Another metabolic process identified through the RNA-seq analysis was the upregulation of glucose metabolism and trehalose biosynthesis. To confirm these results, we measured the expression of trehalose-6-phosphate-synthase 1 (SlT6PS1), the enzyme involved in trehalose-6-phosphate utilizing UDP-glucose and Glucose-6-phosphate as precursors [26]. Our results indicated a positive effect of ALPAN ${ }^{\circledR}$ application in inducing the expression of SIT6PS1 after one day of water deficit to increase the adaptation of young tomato seedlings to water deficit conditions (Figure 8, dark green bars).
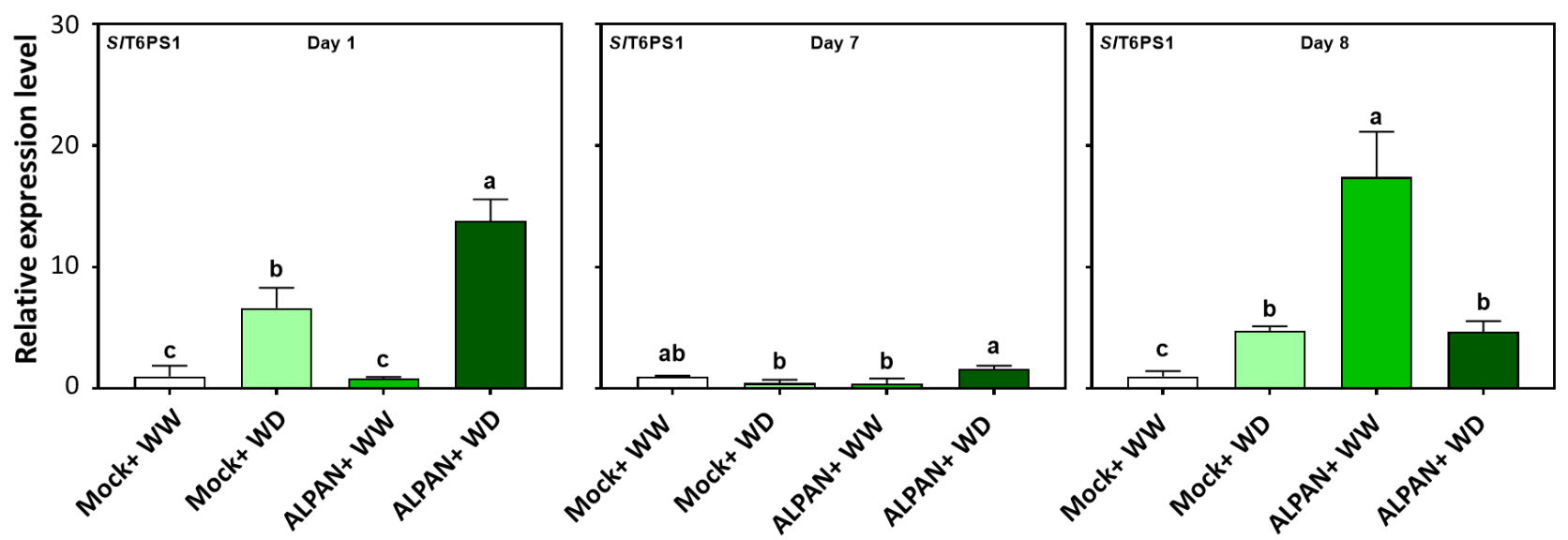

Figure 8. Expression levels of SIT6PS1 after 1, 7, and 8 days of the initiation of the water deficit stress. $\mathrm{WW}=$ well watered, $\mathrm{WD}=$ water deficit. Error bars above histogram columns represent the standard deviation of four independent biological replicates in each experimental group at each sampling timepoint. The statistical data were analyzed with the use of the one-way ANOVA and Tukey's post hoc tests, and a statistically significant difference $(p$-value $<0.05)$ is denoted by a different letter above a histogram column.

ALPAN $^{\circledR}$ application was able to modify the chloroplastic redox regulatory mechanism. In Arabidopsis thaliana and Nicotiana benthamiana the interaction between plastidial thioredoxin $\mathrm{z}(T R X)$ and fructokinase-like 1 (FLN1) is essential for chloroplast development [27]. Our results showed an increase in the expression levels of SlFLN1 (Figure 9, dark green bars) and SITRX (data not shown) during the first day of drought stress.
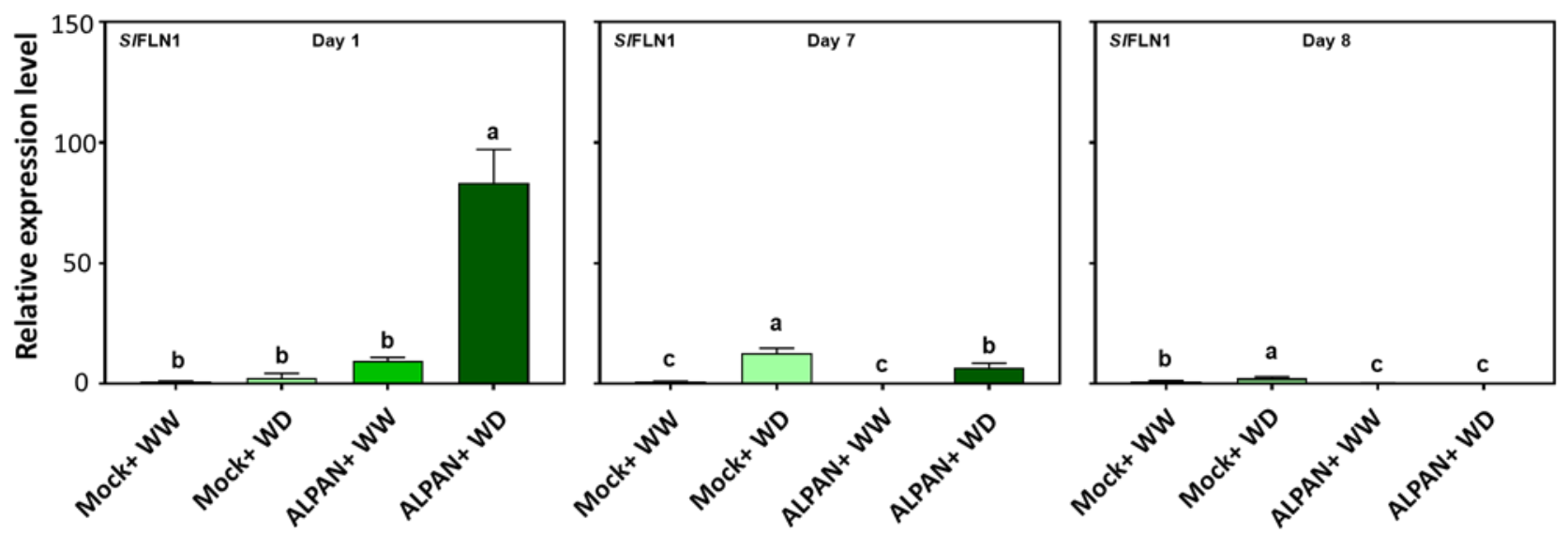

Figure 9. Expression levels of SIFLN1 after 1, 7, and 8 days of the initiation of the water deficit stress. $\mathrm{WW}=$ well watered, $\mathrm{WD}=$ water deficit. Error bars above histogram columns represent the standard deviation of four independent biological replicates in each experimental group at each sampling timepoint. The statistical data were analyzed with the use of the one-way ANOVA and Tukey's post hoc tests, and a statistically significant difference $(p$-value $<0.05)$ is denoted by a different letter above a histogram column. 
ALPAN $^{\circledR}$ application positively affected the process of nitrogen assimilation, and our results indicated a positive effect on the expression of phenylalanine ammonia lyase (SIPAL1) (Figure 10). SIPAL1 is an enzyme that helps in the catalyzation of L-phenylalanine to trans-cinnamic acid and ammonium, in which the conversion can be regarded as a critical step in inducing the metabolism in a plant [28].
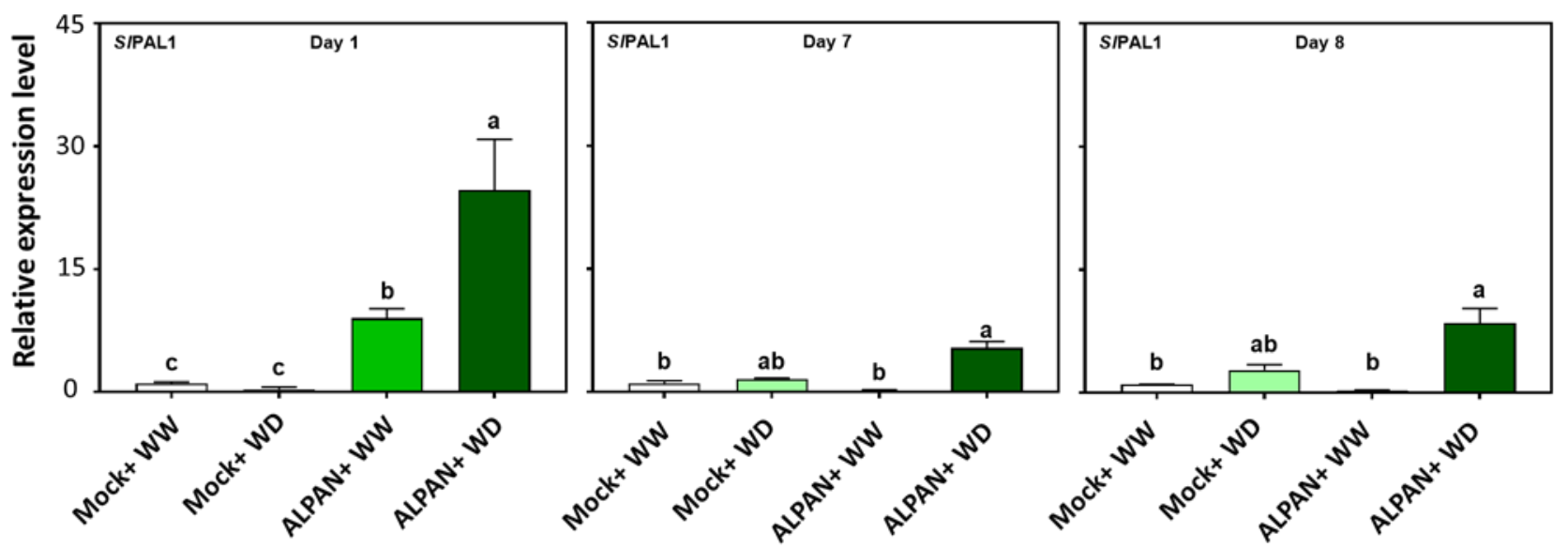

Figure 10. Expression levels of SIPAL1 after 1, 7, and 8 days of the initiation of the stress. WW = well watered, $\mathrm{WD}=$ water deficit. Error bars above histogram columns represent the standard deviation of four independent biological replicates in each experimental group at each sampling timepoint. The statistical data were analyzed with the use of the one-way ANOVA and Tukey's post hoc tests, and a statistically significant difference $(p$-value $<0.05)$ is denoted by a different letter above a histogram column.

\section{Discussion}

Plant biostimulants have gained deeper attention recently as sustainable tools to mitigate the negative effects of extreme weather events that result from climate change caused by human activities [29]. ALPAN ${ }^{\circledR}$ is a natural biostimulant based on the complexation of plant-derived pool of polyphenols with an essential macronutrient, magnesium. Our study presents an insight into the positive effects of ALPAN $^{\circledR}$ treatment on tomato seedling exposed to mild water deficit conditions for seven days. ALPAN ${ }^{\circledR}$ foliar application was shown to modulate the transcriptional and eco-physiological responses to short (one day) and longer (seven days) periods of water deficit conditions.

In the short term, ALPAN ${ }^{\circledR}$ application was able to regulate processes involved in abscisic acid metabolism, non-structural carbohydrates metabolism, and source to sink translocation. Those three processes, among others, play a significant role in alleviating the negative effects of water shortage on plants [30,31]. In addition, ALPAN $^{\circledR}$ application showed a positive impact on stabilizing the levels of photosynthetic pigments that play a pivotal role in maintaining the process of photosynthesis under low water conditions and regulating a moderate increase in proline accumulation since an over-accumulation of proline can expose toxic effects on plant tissue [32].

In the long-term, our data indicate a crucial role for ALPAN ${ }^{\circledR}$ in maintaining a functional photosynthetic apparatus through the stabilization of the levels of chlorophyll $a$, chlorophyll $b$, and total carotenoids after seven days of water deficit. Moreover, it was able to prevent ROS-mediated cell death that results from the loss of cell membrane integrity by keeping a low percentage of electrolyte leakage, an assay used to assess the stress-induced injury of plant tissues and an indicator of plant stress tolerance $[33,34]$. Additionally, RNAseq showed that ALPAN $^{\circledR}$ was able to positively modify processes involved in: protein post translation modifications such as protein phosphorylation and dephosphorylation, cellular organelles modifications such as apoplast and nucleus, the sink to source translocation 
process, and nitrogen assimilation. Such processes are known to be negatively affected when plants are exposed to heterogenous environmental conditions such as drought.

In conclusion, $\mathrm{ALPAN}^{\circledR}$ (based on $\mathrm{EnNuVi}^{\circledR}$ technology) is an innovative, naturally derived biostimulant based on the combination of polyphenols and magnesium that can be added to the arsenal of tools aiming to serve farmers in mitigating the negative effects of reduced rainfall or the decreasing availability of irrigation water, which in turn affect plant growth and development leading to a great reduction in yield.

\section{Materials and Methods}

\subsection{Plant Material, Growing Conditions, and Experimental Setup}

Tomato (Solanum lycopersicum) plant (cv. Rio Grande) seeds were obtained from local seed supplier and germinated in the growth chamber $\left(12 \mathrm{~h}\right.$ light $/ 12 \mathrm{~h}$ dark; $200 \mu \mathrm{m} \cdot \mathrm{m}^{-2} \cdot \mathrm{S}^{-2}$ ). One week after germination the plants were transplanted into $20 \mathrm{~cm}$ pots with a homogenous and equal weight of substrate mixture (two parts peat moss: one part perlite), and the watering was maintained until they reached 1 month old, a stage where the four leaves became well developed $(\mathrm{BBCH}=104)$. Then, the plants $(\mathrm{N}=32)$ were randomly assigned to four different experimental groups (four biological replicates; two plants per replicate): Mock well watered (Mock + WW), Mock water deficit (Mock + WD), ALPAN ${ }^{\circledR}$ well watered $\left(\right.$ ALPAN $\left.^{\circledR}+W W\right)$, and ALPAN ${ }^{\circledR}$ water deficit (ALPAN + WD). Briefly, plants were sprayed with $20 \mathrm{~mL}$ of water (mock) or ALPAN ${ }^{\circledR}$ (proprietary composition, SCL Italia SpA) at dilution rate of $0.1 \% v / v$, one day prior to water deficit initiation (day $0 ; \mathrm{T} 1$ ).

The first two samplings were sprayed one (T2) and seven (T3) days after the start of the water deficit, to assess the plant response after short and longer periods of water deficit conditions, respectively. Then at day 7 , plants were re-watered to the full pot capacity and sprayed for a second treatment with water (mock) or ALPAN ${ }^{\circledR}$. Then, one day after rewatering, a third sampling took place (day 8; T4) (Figure 11).
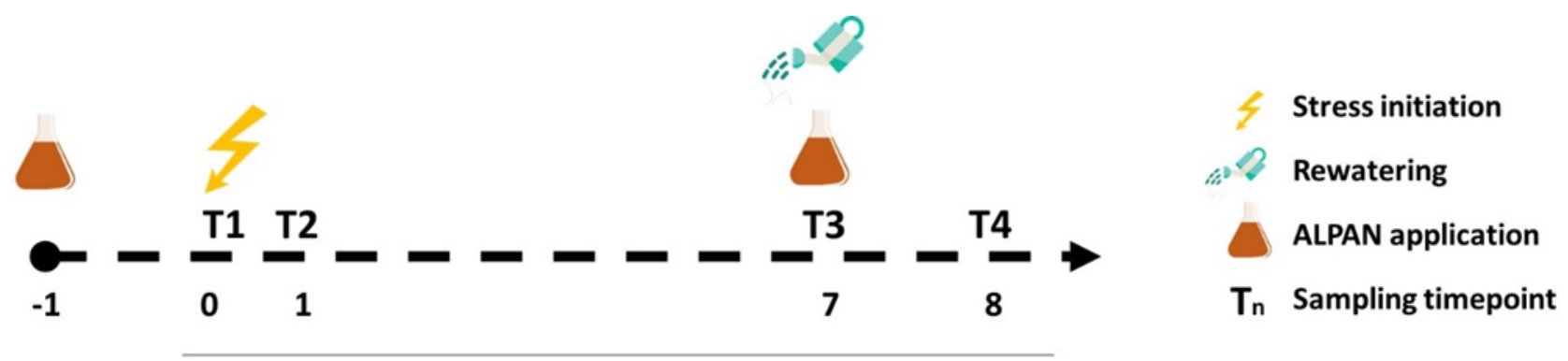

\section{Days after stress}

Figure 11. Schematic representation of the experimental design with the sampling time points for molecular and physiological analysis. Four biological replicates in each experimental group at each timepoint.

Leaf samples were collected and immediately frozen in liquid nitrogen and stored in $-80{ }^{\circ} \mathrm{C}$ for further molecular and physiological analysis. Five independent experiments were carried out to perform each analysis (molecular analysis, pigments quantification, MDA quantification, EL estimation, proline quantification), applying the same experimental design with four independent biological replicates sampled from each experimental group at different sampling timepoint.

\subsection{Chlorophyll and Carotenoids Quantification}

Pigments were extracted according to Hiscox and Israelstam [35] with slight modifications. Briefly, $100 \mathrm{mg}$ of frozen ground tissue were dissolved in $1 \mathrm{~mL}$ preheated DMSO using $1.5 \mathrm{~mL}$ Eppendorf tube and incubated for $15 \mathrm{~min}$ at $95^{\circ} \mathrm{C}$. A total of $900 \mu \mathrm{L}$ of the supernatant was recovered into $2 \mathrm{~mL}$ Eppendorf tube through centrifugation $(14,000 \mathrm{rpm}$ for $10 \mathrm{~min}$ ) and the pellet was redissolved with $1 \mathrm{~mL}$ preheated DMSO and incubated 
again for $15 \mathrm{~min}$. Another $900 \mu \mathrm{L}$ were recovered, then $200 \mu \mathrm{L}$ of DMSO was added to obtain a final volume of $2 \mathrm{~mL}$. The quantification of chlorophyll $a$ and chlorophyll $b$ were calculated according to Arnon [36], while carotenoids were calculated according to Kirk and Allen [37].

\subsection{Membrane Integrity Assessment by Conductivity of Electrolyte Leakage}

Membrane integrity was assessed by conductivity measurements of electrolyte leakage (EL) from four biological replicates, as reported in [38] with slight modifications. Briefly, 20 discs were cut from leaves punched using a cork borer and immersed in $10 \mathrm{~mL}$ double-deionized sterile water in $50 \mathrm{~mL}$ falcons. Samples were kept in agitation at room temperature with an orbital shaker (200 rpm) for $4 \mathrm{~h}$, and conductivity was measured in the balanced bathing solution with a conductivity meter, this corresponds to the initial conductivity $\left(C_{i}\right)$. To determine the values corresponding to maximum electrolyte leakage from lysed leaf material, conductivity was then measured after samples were autoclaved and the liquid cooled down, this corresponds to the total conductivity $\left(C_{t}\right)$. Percent ion leakage was expressed as the ratio of the two values multiplied by 100 .

\subsection{Lipid Peroxidation by Quantification of Malondialdehyde Levels}

Lipid peroxidation was analysed with the thiobarbituric acid test, which determines malondialdehyde (MDA) as end product of lipid peroxidation [39]. Briefly, $50 \mathrm{mg}$ aerial tissue was homogenized in $1 \mathrm{~mL}$ frozen $80 \%$ ethanol $(v / v)$ on ice. Following centrifugation at $16,000 \times \mathrm{g}$ for $20 \mathrm{~min}$ at $4{ }^{\circ} \mathrm{C}$, the supernatant $(0.5 \mathrm{~mL})$ was mixed with $0.5 \mathrm{~mL} 20 \%$ trichloroacetic acid $(w / v)$ containing $0.65 \%$ thiobarbituric acid $(w / v)$. The mixture was incubated at $95^{\circ} \mathrm{C}$ for $30 \mathrm{~min}$ and then immediately cooled in an ice bath. After centrifugation at $10,000 \times g$ for $10 \mathrm{~min}$ at $4{ }^{\circ} \mathrm{C}$, the absorbance of the supernatant was measured at $532 \mathrm{~nm}$, subtracting the value for nonspecific absorption at $600 \mathrm{~nm}$. The MDA concentration was calculated from the extinction coefficient $155 \mathrm{mM}^{-1} \mathrm{~cm}^{-1}$.

\subsection{Cellular Proline Quantification}

Proline quantification was performed according to [40]. Briefly, $50 \mathrm{mg}$ leaf tissue were ground and resuspended in $40 \%$ Ethanol and left overnight at $4{ }^{\circ} \mathrm{C}$. The extract was then centrifuged and the $250 \mu \mathrm{L}$ of the supernatant was mixed in $1.5 \mathrm{~mL}$ Eppendorf tube with $1000 \mu \mathrm{L}$ of the reaction mix and $250 \mu \mathrm{L}$ Ethanol (40\%). The tube was well mixed, and the content was transferred to cuvette and quantification was performed using the peak absorbance wavelength $(520 \mathrm{~nm})$.

\subsection{RNA Isolation, cDNA Library Construction, and Gene Expression Analysis}

Total RNA was extracted from leaf samples using Qiagen RNA isolation kit (Qiagen, Germany) according to the manufacturer's instructions. DNA was removed by digestion with RNase-free DNase, and RNA was purified and concentrated using an RNeasy column (Qiagen, Germany). RNA quality was evaluated by 1\% agarose gel electrophoresis for 28S/18S rRNA band intensity (2:1) and Agilent 2100 Bioanalyzer. The samples were quantified using Nanodrop 2000 spectrophotometer (Thermo Fisher Scientific, Waltham, MA, USA).The A260/A280 nm ratios for all samples ranged between 1.8 and 2.1. Only the RNA samples with 260:280 ratio ranging between 1.9 and 2.1 and RNA integrity number (RIN) > 8.0 were used for further analysis.

Equal amounts of RNA were subsequently subjected to genomic DNA removal by aid of the RQ1 DNase kit (Promega) and cDNA synthesis using the Maxima First Strand cDNA Synthesis Kit for RT-qPCR, with dsDNase (Product no. K1671, Life Technologies, Carlsbad, CA, USA), following the manufacturer's instructions. Four biological replicates in each experimental group.

To quantify gene expression, qPCR analysis was carried out with the ABI Prism 7300 sequence detection system (Applied Biosystems, Waltham, MA, USA) using the Power Up SYBR Green master mix (Life Technologies). Relative quantification of the 
expression (qPCR analysis) of each individual gene was performed using the comparative threshold cycle method [41]. Elongation Factor 1 Alpha (SlEF1 $\alpha$ ) was used as internal control according to Lacerda et al. [42]. qRT-PCR analysis was performed on single samples collected at T2, T3, and T4. Table 1 shows the sequence of the forward and reverse primers used for each gene.

Table 1. The sequences for the primers used in the amplification of qPCR products.

\begin{tabular}{cccc}
\hline Locus & Gene & Froward Primer & \multicolumn{1}{c}{ Reverse Primer } \\
\hline Solyc01g108020 & SlEF1 $\alpha$ & TGGAATTGGAACTGTCCCCG & GAGCTTCGTGGTGCATCTCT \\
Solyc02g084850 & SlTAS14 & TCCCTACTCCCTGAACCTCC & CAGTCTTGCGCATTTGGTCT \\
Solyc09g011850 & SlFLN1 & AGTGCAAACAAGGGCTGTCA & TCGGAGCTAAGCAGTGAATCC \\
Solyc12g009400 & SlPDH1 & TGCTGCACGAGATCCTATCAG & TCATCCGCAAATTCGACAGC \\
Solyc10g086180 & SlPAL6 & TTTCCAGGGCACTCCCATTG & GTCGTTGACAAGCTCGGAGA \\
Solyc07g006500 & SlT6PS1 & GGTGTTTGCTCTGTTTATGGTGT & CAGAACAGTCATCAAGATTAAGCAG \\
\hline
\end{tabular}

\subsection{RNA-Seq Analysis and Library Construction}

RNA-Seq libraries were prepared with Illumina TruSeq Stranded mRNA Sample Preparation Kit as per the manufacturer's instructions. The experiment included two genotypes under two conditions (each data point pooled from 12 plants), which resulted in four RNA-Seq libraries. These libraries were sequenced on Illumina HiSeq 2000 platform (Illumina, San Diego, CA, USA) with 100 nucleotide pair-end reads.

\subsection{Statistical Analysis}

Data were statistically analyzed using GraphPad Prism version 8.0 software package and Tukey's post hoc tests $(p \leq 0.05)$, using the treatments as a statistical parameter to determine significant differences among treatment means.

\section{Patent}

US patent $\mathrm{n}^{\circ}$ : US11168035B2, Italian patent $\mathrm{n}^{\circ}: 102016000126419$.

Author Contributions: Conceptualization, H.H. and V.C.; methodology, H.H. and V.C.; formal analysis, H.H.; investigation, H.H. and L.C.; resources, S.A.; writing-original draft preparation, H.H.; writing, review and editing, H.H. and V.C.; supervision, V.C. All authors have read and agreed to the published version of the manuscript.

Funding: This work was supported by EU's LIFE programme under Grant agreement LIFE18 ENV/IT/000304 (LIFE ENVision project).

Institutional Review Board Statement: Not applicable.

Informed Consent Statement: Not applicable.

Data Availability Statement: Available upon request to the authors.

Acknowledgments: We would like to thank: Sequentia Biotech SL for their assistance in RNA-seq and qPCR analysis; Chiara Ranaldi for her contribution in the setup of the experiments. EnNuVi ${ }^{\circledR}$ and Alpan ${ }^{\circledR}$ are trademarks registered by SCL Italia in Italy and other countries.

Conflicts of Interest: The authors declare no conflict in interest.

\section{References}

1. United Nations, Department of Economic and Social Affairs, Population Division. World Population Prospects 2019: Highlights (ST/ESA/SER.A/423); United Nations: New York, NY, USA, 2019.

2. IPCC. Climate Change 2021: The Physical Science Basis. Contribution of Working Group I to the Sixth Assessment Report of the Intergovernmental Panel on Climate Change; Masson-Delmotte, V., Zhai, P., Pirani, A., Connors, S.L., Péan, C., Berger, S., Caud, N., Chen, Y., Goldfarb, L., Gomis, M.I., et al., Eds.; Cambridge University Press: Cambridge, UK, 2021.

3. FAO. The State of Food and Agriculture 2019: Moving forward on Food Loss and Waste Reduction; FAO: Rome, Italy, 2020. 
4. Singh, D.; Laxmi, A. Transcriptional regulation of drought response: A tortuous network of transcriptional factors. Front. Plant Sci. 2015, 6, 895. [CrossRef] [PubMed]

5. Kaur, G.; Asthir, B. Molecular responses to drought stress in plants. Biol. Plant. 2017, 61, 201-209. [CrossRef]

6. Tripathy, B.C.; Oelmüller, R. Reactive oxygen species generation and signaling in plants. Plant Signal. Behav. 2012, 7, 1621-1633. [CrossRef] [PubMed]

7. Miller, G.; Suzuki, N.; Ciftci-Yilmaz, S.; Mittler, R. Reactive oxygen species homeostasis and signalling during drought and salinity stresses. Plant Cell Environ. 2010, 33, 453-467. [CrossRef]

8. Ashraf, M.; Harris, P.J.C. Photosynthesis under stressful environments: An overview. Photosynthetica 2013, 51, 163-190. [CrossRef]

9. He, M.; Dijkstra, F.A. Drought effect on plant nitrogen and phosphorus: A meta-analysis. New Phytol. 2014, $204,924-931$. [CrossRef]

10. Keller, F.; Ludlow, M.M. Carbohydrate Metabolism in Drought-Stressed Leaves of Pigeonpea (Cajanus cajan). J. Exp. Bot. 1993, 44, 1351-1359. [CrossRef]

11. Gupta, A.K.; Kaur, N. Sugar signalling and gene expression in relation to carbohydrate metabolism under abiotic stresses in plants. J. Biosci. 2005, 30, 761-776. [CrossRef]

12. Guerra, D.; Crosatti, C.; Khoshro, H.H.; Mastrangelo, A.M.; Mica, E.; Mazzucotelli, E. Post-transcriptional and post-translational regulations of drought and heat response in plants: A spider's web of mechanisms. Front. Plant Sci. 2015, 6, 57. [CrossRef]

13. Akula, R.; Ravishankar, G.A. Influence of abiotic stress signals on secondary metabolites in plants. Plant Signal. Behav. 2011, 6, 1720-1731. [CrossRef]

14. Šamec, D.; Karalija, E.; Šola, I.; Vujčić Bok, V.; Salopek-Sondi, B. The Role of Polyphenols in Abiotic Stress Response: The Influence of Molecular Structure. Plants 2021, 10, 118. [CrossRef] [PubMed]

15. Sharma, A.; Shahzad, B.; Rehman, A.; Bhardwaj, R.; Landi, M.; Zheng, B. Response of Phenylpropanoid Pathway and the Role of Polyphenols in Plants under Abiotic Stress. Molecules 2019, 24, 2452. [CrossRef] [PubMed]

16. Pandey, N. Role of Plant Nutrients in Plant Growth and Physiology. In Plant Nutrients and Abiotic Stress Tolerance; Springer: Singapor, 2018; pp. 51-93.

17. Tavanti, T.R.; de Melo, A.A.R.; Moreira, L.D.K.; Sanchez, D.E.J.; Silva, R.D.S.; da Silva, R.M.; dos Reis, A.R. Micronutrient fertilization enhances ROS scavenging system for alleviation of abiotic stresses in plants. Plant Physiol. Biochem. 2021, 160, 386-396. [CrossRef] [PubMed]

18. Van Oosten, M.J.; Pepe, O.; De Pascale, S.; Silletti, S.; Maggio, A. The role of biostimulants and bioeffectors as alleviators of abiotic stress in crop plants. Chem. Biol. Technol. Agric. 2017, 4, 5. [CrossRef]

19. Bulgari, R.; Franzoni, G.; Ferrante, A. Biostimulants Application in Horticultural Crops under Abiotic Stress Conditions. Agronomy 2019, 9, 306. [CrossRef]

20. Shahrajabian, M.; Chaski, C.; Polyzos, N.; Petropoulos, S. Biostimulants Application: A Low Input Cropping Management Tool for Sustainable Farming of Vegetables. Biomolecules 2021, 11, 698. [CrossRef]

21. Havaux, M. Carotenoids as membrane stabilizers in chloroplasts. Trends Plant Sci. 1998, 3, 147-151. [CrossRef]

22. Kalaji, H.M.; Jajoo, A.; Oukarroum, A.; Brestic, M.; Zivcak, M.; Samborska, I.A.; Cetner, M.D.; Łukasik, I.; Goltsev, V.; Ladle, R.J. Chlorophyll a fluorescence as a tool to monitor physiological status of plants under abiotic stress conditions. Acta Physiol. Plant. 2016, 38, 1-11. [CrossRef]

23. Parra, M.D.M.; del Pozo, O.; Luna, R.; Godoy, J.A.; Pintor-Toro, J. Structure of the dehydrin tas 14 gene of tomato and its developmental and environmental regulation in transgenic tobacco. Plant Mol. Biol. 1996, 32, 453-460. [CrossRef]

24. Muñoz-Mayor, A.; Pineda, B.; Garcia-Abellán, J.O.; Antón, T.; Garcia-Sogo, B.; Sánchez-Bel, P.; Flores, F.B.; Atarés, A.; Angosto, T.; Pintor-Toro, J.A.; et al. Overexpression of dehydrin tas14 gene improves the osmotic stress imposed by drought and salinity in tomato. J. Plant Physiol. 2012, 169, 459-468. [CrossRef]

25. Weraduwage, S.M.; Micallef, M.C.; Marillia, E.-F.; Taylor, D.C.; Grodzinski, B.; Micallef, B.J. Increased mtPDH Activity Through Antisense Inhibition of Mitochondrial Pyruvate Dehydrogenase Kinase Enhances Inflorescence Initiation, and Inflorescence Growth and Harvest Index at Elevated CO2 in Arabidopsis thaliana. Front. Plant Sci. 2016, 7, 1-12. [CrossRef] [PubMed]

26. Ponnu, J.; Wahl, V.; Schmid, M. Trehalose-6-Phosphate: Connecting Plant Metabolism and Development. Front. Plant Sci. 2011, 2, 70. [CrossRef] [PubMed]

27. Arsova, B.; Hoja, U.; Wimmelbacher, M.; Greiner, E.; Üstün, S.; Melzer, M.; Petersen, K.; Lein, W.; Börnke, F. Plastidial Thioredoxin z Interacts with Two Fructokinase-Like Proteins in a Thiol-Dependent Manner: Evidence for an Essential Role in Chloroplast Development in Arabidopsis and Nicotiana benthamiana. Plant Cell 2010, 22, 1498-1515. [CrossRef] [PubMed]

28. Hyun, M.W.; Yun, Y.H.; Kim, J.Y.; Kim, S.H. Fungal and Plant Phenylalanine Ammonia-lyase. Mycobiology 2011, 39, 257-265. [CrossRef] [PubMed]

29. Del Buono, D. Can biostimulants be used to mitigate the effect of anthropogenic climate change on agriculture? It is time to respond. Sci. Total Environ. 2021, 751, 141763. [CrossRef] [PubMed]

30. Moles, T.M.; Mariotti, L.; De Pedro, L.F.; Guglielminetti, L.; Picciarelli, P.; Scartazza, A. Drought induced changes of leaf-to-root relationships in two tomato genotypes. Plant Physiol. Biochem. 2018, 128, 24-31. [CrossRef]

31. Rodrigues, J.; Inzé, D.; Nelissen, H.; Saibo, N.J. Source-Sink Regulation in Crops under Water Deficit. Trends Plant Sci. 2019, 24, 652-663. [CrossRef] 
32. Hayat, S.; Hayat, Q.; Alyemeni, M.N.; Wani, A.S.; Pichtel, J.; Ahmad, A. Role of proline under changing environments: A review. Plant Signal. Behav. 2012, 7, 1456-1466. [CrossRef]

33. Blum, A.; Ebercon, A. Cell Membrane Stability as a Measure of Drought and Heat Tolerance in Wheat1. Crop Sci. 1981, 21, 43-47. [CrossRef]

34. Lee, B.-H.; Zhu, J.-K. Phenotypic Analysis of Arabidopsis Mutants: Electrolyte Leakage after Freezing Stress. Cold Spring Harb. Protoc. 2010, 2010, 4970. [CrossRef]

35. Hiscox, J.D.; Israelstam, G.F. A method for the extraction of chlorophyll from leaf tissue without maceration. Can. J. Bot. 1979, 57, 1332-1334. [CrossRef]

36. Arnon, D.I. Copper enzymes in isolated chloroplasts. Polyphenoloxidase in beta vulgaris. Plant Physiol. 1949, 24, 1-15. [CrossRef] [PubMed]

37. Kirk, J.T.O.; Allen, R.L. Dependence of chloroplast pigment synthesis on protein synthesis: Effect of actidione. Biochem. Biophys. Res. Commun. 1965, 21, 523-530. [CrossRef]

38. Pétriacq, P.; Ton, J.; Patrit, O.; Tcherkez, G.; Gakière, B. NAD Acts as an Integral Regulator of Multiple Defense Layers. Plant Physiol. 2016, 172, 1465-1479. [CrossRef]

39. Hodges, D.M.; DeLong, J.M.; Forney, C.F.; Prange, R.K. Improving the thiobarbituric acid-reactive-substances assay for estimating lipid peroxidation in plant tissues containing anthocyanin and other interfering compounds. Planta 1999, 207, 604-611. [CrossRef]

40. Bates, L.S.; Waldren, R.P.; Teare, I.D. Rapid determination of free proline for water-stress studies. Plant Soil 1973, 39, $205-207$. [CrossRef]

41. Livak, K.J.; Schmittgen, T.D. Analysis of Relative Gene Expression Data Using Real-Time Quantitative PCR and the $2^{-\Delta \Delta C T}$ Method. Methods 2001, 25, 402-408. [CrossRef]

42. Lacerda, A.L.M.; Fonseca, L.N.; Blawid, R.; Boiteux, L.S.; Ribeiro, S.G.; Brasileiro, A.C.M. Reference Gene Selection for qPCR Analysis in Tomato-Bipartite Begomovirus Interaction and Validation in Additional Tomato-Virus Pathosystems. PLoS ONE 2015, 10, e0136820. [CrossRef] 